\title{
Excess mortality among Swedish chimney sweeps
}

\author{
P GUSTAVSSON, ${ }^{1}$ ANNIKA GUSTAVSSON, ${ }^{2}$ C HOGSTEDT ${ }^{12}$
}

From the Department of Occupational Medicine, ${ }^{1}$ Karolinska Hospital, S-10401 Stockholm, and Section of Occupational Medicine, ${ }^{2}$ Research Department, National Board of Occupational Safety and Health, S-171 84 Solna, Sweden

ABSTRACT In a cohort study of 5464 union organised Swedish chimney sweeps employed at any time between 1918 and 1980 mortality was studied from 1951 to 1982 with national statistics used as å reference. Follow up was possible for $98.6 \%$ of the individuals: 717 deaths were observed agains 540 expected. There was an increased mortality from coronary heart disease, respiratory diseases $\overrightarrow{+}$ and several types of malignant tumours. Lung cancer mortality was significantly increased and positively correlated to the number of years employed. A fivefold risk increase for oesophagea $\mathbb{N}$ cancer and liver cancer was found. The increased mortality could be attributed to exposure to combustion products in the work environment but not to smoking habits.

In 1775 Sir Percival Pott published his classic case reports on scrotal cancer among London chimney sweeps. ${ }^{1}$ Only recently, however, have epidemiological studies shown that chimney sweeps are still at an increased risk of cancer and other diseases. $^{2-5}$ Our first study on long time employed chimney sweeps showed an increased mortality from malignant diseases such as cancer of the lung, oesophagus, and liver and from circulatory and respiratory diseases. ${ }^{2}$ Some of these results were later supported by a Danish investigation showing an increased mortality from lung and stomach cancer and coronary heart disease. ${ }^{34}$ In the present report we have doubled the size of the study group by including all Swedish chimney sweeps and extended the follow up period in order to investigate exposure response relations.

During their work, chimney sweeps are exposed to soot and gases from the burning of wood, coal, coke, and mineral oil. Soot contains polycyclic aromatic hydrocarbons (PAH), a class of compounds with well documented carcinogenic properties. ${ }^{6}$ Soot also contains the metals $\mathrm{As}, \mathrm{Pb}, \mathrm{Cr}, \mathrm{Co}, \mathrm{Cu}, \mathrm{Ni}, \mathrm{Zn}$, and $\mathrm{V}$, several of which are suspected or accepted carcinogens. Chimney sweeps are also exposed to sulphur dioxide, asbestos, and silica. Organic solvents are used for degreasing ventilatory equipment. ${ }^{78}$

The chimney sweeps' work environment has continuously changed during the twentieth century, mainly because the burning of oil has replaced the burning of wood, coal, and coke but also due to improvements in occupational hygiene. Since the

Accepted 13 October 1986 1950s oil has been the dominant fuel for heating buildings in Sweden. Soot from oil fuelled burners contain sulphur dioxide which irritates the mucous@ membranes in the airways and eyes. The burning of wood, on the other hand, may give rise to higher 1 ev $\infty 0$ els of PAH, especially in small fireplaces. ${ }^{8}$

\section{Material and methods}

The records of the Swedish Chimney Sweeps Trade Union were used as the source material for the study All individuals enrolled at any time between 1918, 의 when the union was established, and 1980 were primarily included in the cohort. Name, date and place of birth, civil registration number (if indicated), and time for joining and leaving the union was recorded.

A total of 5542 male chimney sweeps were identified in the register. The trade union rate among chimney sweeps in Sweden is around $95 \%$ and the study thus has the character of a total nationa investigation of the trade. The union records contain information about any chimney sweep work before joining the union and the first year of work was regis $\frac{D}{2}$ tered as the first year of exposure. Some chimneye. sweeps become a master, leave the union, and starf their own enterprise. Since most of their work is administrative, they have been considered unexposecos in the calculation of total exposure time.

Follow up of individuals was obtained by matching civil registration numbers with a computerised regise ter of the living population at the National Insuranced Authority. Individuals not identified in this register ${ }^{?}$ were traced through death and burial books of the 
Table 1. Duration of exposure

\begin{tabular}{lrrr}
\hline Exposure time (years) & No & $\%$ & Cum-\% \\
\hline$<2$ & 959 & 17.6 & 17.6 \\
$2-5$ & 1122 & 20.5 & 38.1 \\
$6-10$ & 1016 & 18.6 & 56.7 \\
$11-20$ & 1350 & 24.7 & 81.4 \\
$21-30$ & 527 & 9.6 & 91.0 \\
$31-40$ & 246 & 4.5 & 95.5 \\
$41-50$ & 154 & 2.8 & 98.4 \\
$\geqslant 51$ & 90 & 1.6 & 100.0 \\
\hline
\end{tabular}

clerical parishes in charge of such data in Sweden. Death certificates coded for underlying cause of death according to WHO rules were obtained from the Swedish Central Bureau of Statistics.

The study period was $1951-82 ; 127$ chimney sweeps had died before 1951, 39 had emigrated, seven were officially registered as missing, and 32 were lost to follow up; vital status was thus traced for $98.6 \%$ of the individuals primarily included. Those who had emigrated, were lost to follow up, or officially registered as missing were excluded from the statistical analysis. The group on which the analyses were performed consists of 5464 individuals. The duration of exposure is shown in table 1.

The observed numbers of deaths were compared with expected numbers, calculated from national mortality statistics. The computations were performed according to the man-years method, counting man-years at risk specific for sex, calendar year, and five year age class. The number of man-years in each stratum was multiplied with the mortality rate in the corresponding stratum of the national statistics and the number of expected cases were added over strata. The summary risk measure obtained is the standardised mortality ratio (SMR) computed as observed/ expected $\times 100$. Confidence intervals for the SMR were computed with an exact method, based on the Poisson distribution. ${ }^{9}$ Latency time is the period from first exposure until start of risk calculation. The computations were performed with a computer program for epidemiological calculations developed at the University of Linköping. ${ }^{10}$ The risk calculations in tables 2,3 , and 4 were restricted to ages under 80 since the accuracy of underlying cause of death may be less reliable at high ages.

\section{Results}

A total of 717 deaths were observed whereas 540 would be expected, calculated without age restriction. This corresponds to an SMR of $133(95 \%$ CI 123-142) and the overall mortality is significantly increased.

Cause specific mortality was calculated up to age 79 (table 2) and significant increases were found for malignant tumours, circulatory diseases, respiratory diseases, and violent deaths. Among the malignancies, a fivefold increased frequency of oesophageal cancer and liver cancer was found. Lung cancer mor-

Table 2 Mortality by cause in Swedish chimney sweeps 1951-82. (Risk calculation up to and including age 79, 106462 person-years)

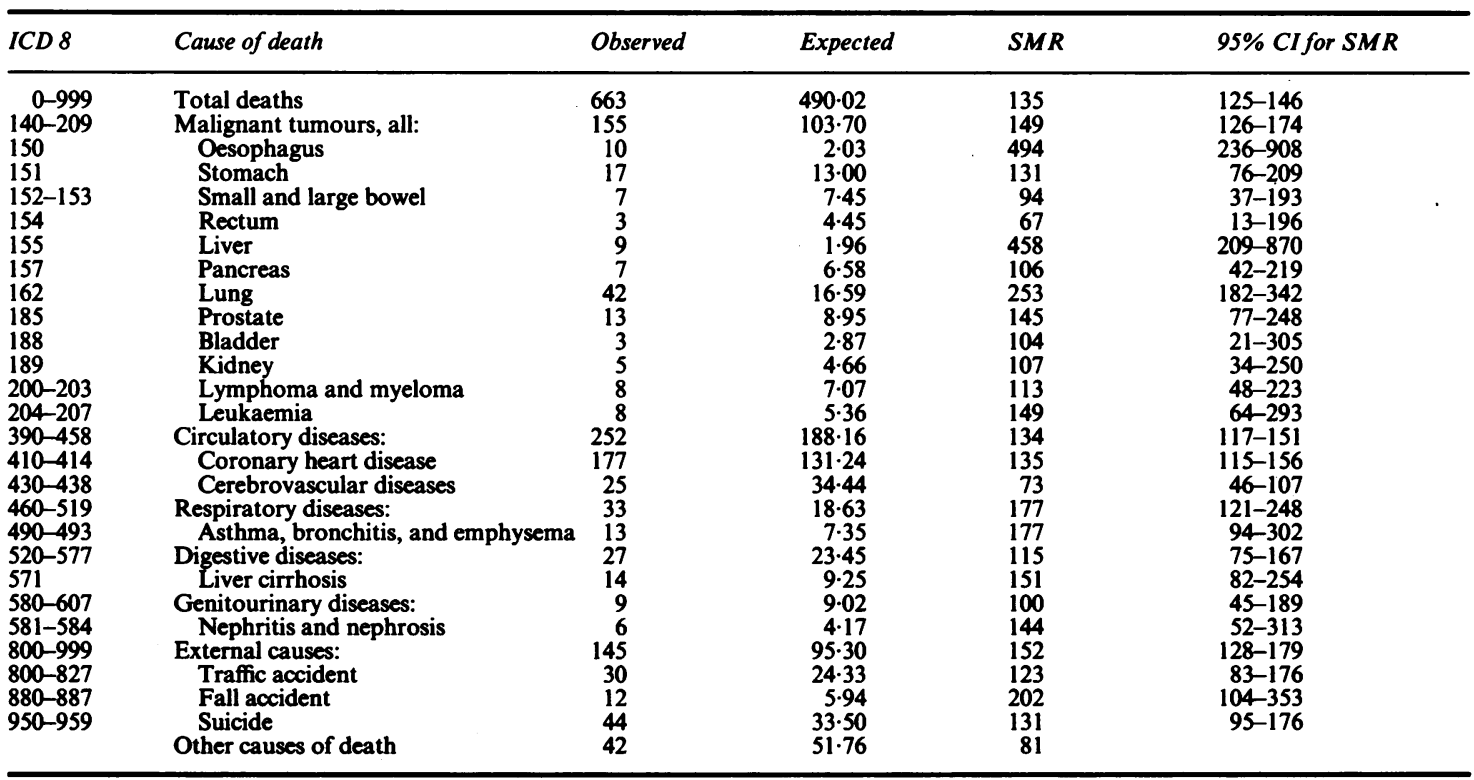

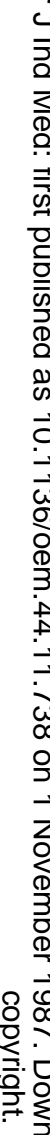


Table 3 Mortality by duration of exposure in Swedish chimney sweeps. (Number of observed cases shown in parentheses. Risk calculation up to and including age 79. Thirty years latency before observation of risk, 19856 person-years)

\begin{tabular}{|c|c|c|c|c|c|c|}
\hline \multirow[b]{3}{*}{$I C D 8$} & \multirow[b]{3}{*}{ Cause of death } & \multicolumn{4}{|c|}{ Exposure time (years) } & \multirow{3}{*}{$\begin{array}{l}\overrightarrow{\overline{\bar{T}}} \\
\overline{0} \\
\frac{\bar{C}}{\bar{\sigma}}\end{array}$} \\
\hline & & \multirow{2}{*}{$\frac{0-9}{S M R(O b s)}$} & \multirow{2}{*}{$\frac{10-19}{S M R(O b s)}$} & \multirow{2}{*}{$\frac{20-29}{S M R(O b s)}$} & \multirow{2}{*}{$\frac{\geqslant 30}{S M R(O b s)}$} & \\
\hline & & & & & & \\
\hline $\begin{array}{l}0-999 \\
140-209 \\
150 \\
151 \\
155 \\
162 \\
390-458 \\
410-414 \\
430-438 \\
460-519 \\
490-493\end{array}$ & $\begin{array}{l}\text { Total deaths } \\
\text { Malignant tumours: } \\
\text { Oesophagus } \\
\text { Stomach } \\
\text { Liver } \\
\text { Lung } \\
\text { Circulatory diseases: } \\
\text { Coronary heart disease } \\
\text { Cerebrovascular disease } \\
\text { Respiratory diseases: } \\
\text { Asthma, bronchitis, emphysema }\end{array}$ & $\begin{array}{l}175(59) \\
98(8) \\
-(0) \\
247(2) \\
122(2) \\
212(34) \\
191(23) \\
230(5) \\
308(4) \\
323(2)\end{array}$ & $\begin{array}{l}147(126) \\
163(34) \\
417(2) \\
122(3) \\
625(3) \\
249(10) \\
165(69) \\
172(53) \\
144(9) \\
116(4) \\
123(2)\end{array}$ & $\begin{array}{l}142(106) \\
166(30) \\
250(1) \\
124(3) \\
789(3) \\
303(10) \\
115(43) \\
90(24) \\
64(4) \\
213(7) \\
70(1)\end{array}$ & $\begin{array}{l}131(184) \\
187(61) \\
845(6) \\
169(9) \\
345(2) \\
347(18) \\
114(77) \\
127(59) \\
43(6) \\
209(14) \\
299(7)\end{array}$ & $\begin{array}{l}0 \\
0 \\
\omega \\
\overrightarrow{0} \\
\stackrel{\vec{\omega}}{\omega} \\
\frac{0}{0} \\
\frac{\mathbb{D}}{3}\end{array}$ \\
\hline
\end{tabular}

tality was also significantly increased, causing most of the excess malignancies. The mortality in coronary heart disease was significantly increased whereas there was a non-significant tendency towards decreased mortality from cerebrovascular diseases.

Mortality in relation to duration of exposure was calculated with a latency requirement of 30 years (table 3). The SMR for lung cancer was positively correlated to the duration of exposure, indicating an exposure response relation. The SMR for oesophageal cancer was greatest (845) among those exposed for 30 years or more but the number of deaths was small and the trend not firmly established. The excess risk for respiratory diseases applies to all four exposure time categories without an obvious trend whereas the trends for mortality in coronary heart disease and cerebrovascular diseases are reversedthat is, the SMR being lower among long time exposed chimney sweeps.

Table 4 Mortality in chimney sweeps employed exclusively before or after 1 January 1951. (Twenty years latency before observation of risk. Risk calculation up to and including age 79)

\begin{tabular}{lllll}
\hline & & Before 195I & & After 1951 \\
\cline { 5 - 5 } ICD 8 & Cause of death & $S M R(O b s)$ & & $S M R(O b s)$ \\
\hline $0-999$ & Total deaths & $207(167)$ & & $166(36)$ \\
$140-209$ & Malignant tumours, all: & $250(46)$ & & $153(6)$ \\
150 & Oesophagus & $1006(4)$ & & $-(0)$ \\
151 & Stomach & $271(8)$ & & $-(0)$ \\
155 & Liver & $624(2)$ & & $-(0)$ \\
162 & Lung & $480(14)$ & $154(1)$ \\
$390-458$ & Circulatory diseases: & $217(79)$ & $156(9)$ \\
$410-414$ & Coronary heart disease & $191(48)$ & $201(8)$ \\
$430-438$ & Cerebrovascular diseases & $161(12)$ & $107(1)$ \\
$460-519$ & Respiratory diseases: & $368(13)$ & $-(0)$ \\
$490-493$ & Asthma, bronchitis, & $395(5)$ & & $-(0)$ \\
$800-999$ & axternal causes & $233(16)$ & $240(17)$ \\
\hline
\end{tabular}

The mortality was investigated among chimney sweeps exposed only before or only after 1 Januaryo 1951 (table 4) to discriminate between chimney sweeps exposed mainly to soot from wood, coal, and ${ }^{-}$ coke, and those exposed mainly to soot from mineralo oil. A latency requirement of 20 years was introduced in both groups. The mortality pattern among those exposed only before 1951 resembles that of the wholed cohort, but the risk excesses are even greater for most of the diagnoses. Only 36 deaths had occurred amogggon those employed after 1 January 1951. There was ofe case of lung cancer, 0.65 being expected, and the numi-o ber of deaths due to coronary heart disease was $8.0,3$ whereas 3.98 were expected. The increase of coronaryo heart disease is not statistically significant but theo SMR is almost equal to that among those exposede only before 1951 .

\section{Discussion}

Swedish chimney sweeps have experienced ano increased mortality from cancer of the lung, liver, and oesophagus and from coronary heart disease, respiratory diseases, and violent deaths. The possible occupational and non-occupational causes are dis-ô cussed below.

\section{TOBACCO SMOKING}

Since tobacco smoking is related to an increasedo mortality from lung cancer, coronary heart disease, and oesophageal cancer, it is important to evaluater the influence from smoking habits among the chim- $N$ ney sweeps. Individual smoking data are not available for the full cohort, but in 1972 a health survey was performed among all Swedish chimney sweeps active at that time $(n=1042)$, and the smoking habits were registered. ${ }^{11}$ In 1963 an age weighted random samplees? of the Swedish population of 53000 individuals had 
Table 5 Smoking habits in Swedish chimney sweeps 1972 compared with the national average 1963 (in parentheses). (Percentage distribution of the smoking categories in each age class is shown)

\begin{tabular}{llll}
\hline Age group & $\begin{array}{l}\text { Never } \\
\text { smoked }\end{array}$ & Ex-smokers & $\begin{array}{l}\text { Current } \\
\text { smokers }\end{array}$ \\
\hline$<39$ & $18(29)$ & $15(10)$ & $67(61)$ \\
$40-49$ & $15(28)$ & $15(11)$ & $70(61)$ \\
$50-59$ & $21(29)$ & $21(9)$ & $57(62)$ \\
$60-69$ & $18(35)$ & $26(9)$ & $56(56)$ \\
\hline
\end{tabular}

been investigated with regard to smoking habits. ${ }^{12}$ The results of both investigations are presented in table 5. Among older chimney sweeps, there was a slightly higher frequency of ex-smokers compared with the national average but the differences in younger age groups were small. Based on data from several cohort studies Pike and Henderson calculated the incidence of lung cancer among individuals stopping smoking at different ages in relation to never smokers and current smokers. ${ }^{13}$ These incidence rates were applied to the data in table 5. With allowance for the discrepancies in smoking habits, an increased mortality in lung cancer of $1 \%$ would be expected among the chimney sweeps. Since an SMR of 253 was observed it seems unlikely that smoking habits have contributed significantly to the excess risk for lung cancer, even if some change of habits may have occurred between 1963 and 1972.

\section{OCCUPATIONAL CARCINOGENS}

Lung cancer mortality was significantly raised and positively correlated with exposure time. Chimney sweeps are occupationally exposed to several carcinogens: PAH, arsenic, nickel, chromium, and asbestos. Animal experiments indicate that sulphur dioxide may promote the carginogenic activity of one PAH, benzo(a)pyrene. ${ }^{14}$ It seems clear that the considerable increase of lung cancer mortality may be attributed to the inhalation of chemical carcinogens in the work environment.

A fivefold increased risk of oesophageal cancer was found. Smoking and alcohol habits influence the incidence of oesophageal cancer. ${ }^{15}$ The chimney sweeps' smoking habits cannot explain the high risk increase for this cancer. If the use of alcohol among chimney sweeps was considerably higher than the national average an increased mortality from liver cirrhosis would be expected. The small increase of deaths from this disease was not statistically significant. It seems improbable, therefore, that the fivefold excess of oesophageal cancer is caused by the sweeps' smoking or drinking habits. The incidence of oesophageal cancer varies widely in different parts of the world ${ }^{15}$ and it is particularly high in some parts of southern Africa and the northeast of Iran. A causal relation with pyrolysis products from tobacco and opium has been suspected, since it is common in these areas to chew and swallow the pipe scrapings after smoking. Opium addiction is common in northeast Iran where crude opium and refined opium products are eaten or smoked and the pipe residues are eaten. ${ }^{16}$ The mutagenic activity in opium and its combustion products has been investigated. ${ }^{16-18}$ Crude opium was not mutagenic whereas combustion products of it were highly mutagenic. A three cyclic aromatic hydrocarbon of phenanthrene type and primary aromatic amines had the highest mutagenic activity. ${ }^{1718} \mathrm{PAH}$ of related types are common in soot from chimneys. ${ }^{8}$ The increased risk of oesophageal cancer among the chimney sweeps is probably caused by inhalation of soot particles containing PAH. These particles are deposited in the bronchial mucosa, transported out of the respiratory system by mucociliary clearance, and subsequently swallowed. The carcinogenic effect is then exerted directly on the oesophageal mucosa.

The reason for the excess of liver tumours is obscure. Occupationally induced primary liver cancer has been reported in connection with exposure to organic solvents. ${ }^{1920}$ The Swedish chimney sweeps have been exposed to organic solvents during the past 15 years when degreasing ventilatory equipment. Neither the magnitude of exposure nor the latency time supports an aetiological relation, however.

No deaths from scrotal cancer occurred in the cohort during the study period. This finding is of interest in relation to a special condition in the contract of employment for Swedish chimney sweeps. Since the beginning of this century, chimney sweeps have been given the right to take a bath during working time at the end of the day. This simple arrangement might successfully have prevented the classic occupational hazard among chimney sweeps, although not the other hazards now found.

In our preliminary study of long time employed chimney sweeps an excess of leukaemias was indicated. No further cases of leukaemia have occurred during the extended follow up and no cases occurred among those employed for less than 10 years. The earlier finding might have been caused by chance. We are currently investigating the incidence of cancer in the cohort, and these analyses will give further information regarding non-fatal forms of cancer such as skin cancer and leukaemia.

\section{CIRCULATORY DISEASES}

An excess of deaths from coronary heart disease and a deficit of deaths from cerebrovascular diseases were found. The mortality in coronary heart disease was 
negatively correlated with duration of exposure. This should not, however, be interpreted as evidence against a causal relation since chimney sweeping is physically demanding. Deaths from coronary heart disease are often preceded for several years by symptoms of impaired circulatory function. Individuals with such symptoms are usually not able to stay in the occupation, thus leading to a selection of physically fit individuals among those with long exposure times. Such a mechanism does not operate with regard to lung cancer which is symptomless until its onset, the course being nearly always fatal in a few months or years. Among younger Danish chimney sweeps an even more pronounced increased mortality due to coronary heart disease was found. ${ }^{34}$

What exposures in the working environment could be associated with the excess of coronary heart disease? The increased risk of coronary heart disease among tobacco smokers is well known and an increased growth of atherosclerotic plaques in the aorta has been shown among chickens exposed to PAH. ${ }^{2122}$ Investigations of other occupational groups exposed to PAH, however, such as coke oven workers and gas workers, have not shown a definite excess of coronary heart disease, ${ }^{2324}$ but selection mechanisms make this group of diseases hard to study. Thus there is some evidence that the increased risk for coronary heart disease among the chimney sweeps is caused by the exposure to PAH, possibly in combination with other chemicals occurring in the soot from chimneys but not in coke or gas works. Confounding factors, such as diagnostic bias related only to chimney sweeps and not to the general population, are hard to imagine. Knowledge on chemically induced atherosclerosis is scarce and should be further developed.

\section{RESPIRATORY DISEASES}

During some work operations, chimney sweeps are exposed to high levels of dust and sulphur dioxide. ${ }^{7}$ Since the chimney sweeps' smoking habits do not differ substantially from the national average it seems clear that the excess of deaths from respiratory diseases should be attributed to exposure to dust-for example, metals and gases such as sulphur dioxide, which is a well known respiratory irritant. ${ }^{25}$

\section{VIOLENT DEATHS AND INTOXICATION}

The excess of deaths from external causes is mainly due to factors outside the working environment and may be directly attributed to occupational factors in only a few cases. Four cases of fatal accidents by falling occurred during chimney sweep enrolment but no cases of suffocation or carbon monoxide poisoning were found that could be attributed to the occupation.

\section{Conclusions}

Swedish chimney sweeps have experienced an increased mortality from cancer of the lung, liver, anc oesophagus, coronary heart disease, and respiratory diseases. The 129 excess deaths from these diseases might be attributed to chemical hazards in the chim $\overline{\overline{5}}$ ney sweeps' work environment.

Because of the long latency/induction time for the diseases under study, it cannot yet be evaluated if the improvements in occupational hygiene and the change of fuels from wood, coal, and coke to oil during the recent decades have altered the mortalityw pattern.

It has been known for more than 200 years that the working environment represents a cancer hazard for chimney sweeps. Our results, and those from? Denmark and Germany, clearly indicate that thisoccupation is still associated with serious risks to health and improved working conditions are necessary.

This study was supported by a grant (83-0811) frono the Swedish Work Environment Fund.

\section{References}

1 Pott P. Chirurgical observations relative to the cataract, polyp $\frac{\Omega}{00}$ the nose, the cancer of the scrotum, the different kinds of ruptres and the mortification of the toes and feet. London: Haques? Clarke \& Collins, 1775.

2 Hogstedt C, Andersson K, Frenning B, Gustavsson A. A cohor study on mortality among long time employed Swedish chim ney sweeps. Scand J Work Environ Health 1982;8:72-8.

3 Hansen ES, Olsen JH, Tilt B. Cancer and noncancer mortality of chimney sweeps in Copenhagen. Int $J$ Epidemiol 198? 11:356-61.

4 Hansen ES. Mortality from cancer and ischemic heart disease in Danish chimney sweeps: a five-year follow up. Am $J$ Epidemiat 1984;50:389-97.

5 Kupetz GW. Cancer of the respiratory system and chimney sweeping. Berlin: Humbolt University, 1966. (Academic dissertation in German.)

6 International Agency for Research on Cancer. Monographs on the evaluation of the carcinogenic risks of chemicals to man: polys nuclear aromatic compounds. Part 1. Chemical, environmentait. and experimental data. Vol 32. Lyon: IARC, 1983.

7 Chang G. Chemical health hazards in chimney sweeping. Stockholm: Research Department, National Board of Occupationa Safety and Health, 1980. (Report No 2603/79, in Swedish.)

8 Fehrmann R. Chimney sweeps occupational environment Copenhagen: Danish Work Environment Fund, 1982. (IR Danish.)

9 Geigy scientific tables. Vol 2. Basel: Ciba-Geigy, 1982:222. N

10 Andersson K, Anjou CG, Brodin G, Kling H, Samuelsson P-J. EPILIN; datain, ratin, cohort, search, stat. Computer progrart for cohort studies. User manual. Linköping: University of Links öping, 1982. (In Swedish.)

11 Swensson $\AA$, Swensson A. Chimney sweeps trade union healt survey, 1972. Stockholm: Research department, Nation't Board of Occupational Safety and Health, 1974. (Repor্চ AMMM101/04, in Swedish.)

12 Cederlöf R, Friberg L, Hrubec Z, Lorich U. The relationship af 
Excess mortality among Swedish chimney sweeps

smoking and some social covariables to mortality and cancer morbidity. Stockholm: Department of Environmental Hygiene, Karolinska Institutet, 1975.

13 Pike MC, Henderson BE. Epidemiology of polycyclic hydrocarbons: quantifying the cancer risk from cigarette smoking and air pollution. In: Gelboin HV, Ts'o POP, eds. Polycyclic hydrocarbons and cancer. Vol 3. New York: Academic Press, 1981:317-34.

14 Laskin S, Kuschner M, Drew RT. Studies in pulmonary carcinogenesis. In: Hanna MG, Nettesheim P, Gilbert JR, eds. Inhalation carcinogenesis. Oak Ridge, Tennessee: US Atomic Energy Commission, 1970:321-51. (AEC symposium series, No 18.)

15 Day NE, Munoz N. Esophagus. In: Shottenfield D, Fraumeni $\mathrm{JF}$, eds. Cancer epidemiology and prevention. Philadelphia: Saunders, 1982.

16 Hewer T, Rose E, Ghadirian P, et al. Ingested mutagens from opium and tobacco pyrolysis products and cancer of the oesophagus. Lancet 1978;ii:494-6.

17 Malaveille C, Friesen M, Camus A-M, et al. Mutagens produced by the pyrolysis of opium and its alkoloids as possible risk factors in cancer of the bladder and oesophagus. Carcinogen 1982;3:577-85.

18 Perry PE, Thomson EJ, Vijayalaxmi, Evans HJ, Day NE, Bartsch $\mathrm{H}$. Induction of SCE by opium pyrolysates in $\mathrm{CHO}$ cells and human peripheral blood lymphocytes. Carcinogen 1983;4:277-30.

19 Hardell L, Bengtsson NO, Jonsson U, Eriksson S, Larsson LG. Aetiological aspects on primary liver cancer with special regard to alcohol, organic solvents and acute intermittent porphyriaan epidemiological investigation. Br J Cancer 1984;50:389-97.

20 Hernberg S, Korkala M-J, Asikainen U, Riala R. Primary liver cancer and exposure to solvents. Int Arch Occup Environ Health 1984;54:147-53.

21 Albert RE, Vanderlaan M, Burns FJ, Nishizumi M. Effect of carcinogens on chicken atherosclerosis. Cancer Res 1979; 37:2232-5.

22 Bond JA, Gown AN, Yang HL, Benditt EP, Juchau MB. Further investigations of the capacity of polynuclear aromatic hydrocarbons to elicit atherosclerotic lesions. $J$ Toxicol Environ Health 1981;7:327-35.

23 Doll R, Vessey MP, Beasley RWR, et al. Mortality of gasworkers: final report of a prospective study. Br J Ind Med 1972; 29:394-406

24 Hurley JF, Archibald RMcL, Collings PL, Fanning DM, Jacobsen M, Steele RC. The mortality of coke workers in Britain. Am J Ind Med 1983;4:691-704.

25 Parkes WR. Occupational lung disorders. London: Butterworths, 1983.

\section{Correspondence and editorials}

The British Journal of Industrial Medicine welcomes correspondence relating to any of the material appearing in the journal. Results from preliminary or small scale studies may also be published in the correspondence column if this seems appropriate. Letters should be not more than 500 words in length and contain a minimum of references. Tables and figures should be kept to an absolute minimum. Letters are accepted on the understanding that they may be subject to editorial revision and shortening.

The journal now also publishes editorials which are normally specially commissioned. The Editor welcomes suggestions regarding suitable topics; those wishing to submit an editorial, however, should do so only after discussion with the Editor. 